\title{
Visible Light Communication System Using Silicon Photocell for Energy Gathering and Data Receiving
}

\author{
Xiongbin Chen, ${ }^{1,2}$ Chengyu Min, ${ }^{1}$ and Junqing Guo' \\ ${ }^{1}$ State Key Laboratory of Integrated Optoelectronics, Institute of Semiconductors, Chinese Academy of Sciences, Beijing, China \\ ${ }^{2}$ School of Electronic, Electrical and Communication Engineering, University of Chinese Academy of Sciences, Beijing, China \\ Correspondence should be addressed to Xiongbin Chen; chenxiongbin@semi.ac.cn
}

Received 24 September 2016; Revised 9 December 2016; Accepted 20 December 2016; Published 11 January 2017

Academic Editor: Liang Wu

Copyright (c) 2017 Xiongbin Chen et al. This is an open access article distributed under the Creative Commons Attribution License, which permits unrestricted use, distribution, and reproduction in any medium, provided the original work is properly cited.

Silicon photocell acts as the detector and energy convertor in the VLC system. The system model was set up and simulated in Matlab/Simulink environment. A $10 \mathrm{~Hz}$ square wave was modulated on LED and restored in voltage mode at the receiver. An energy gathering and signal detecting system was demonstrated at the baud rate of 19200 , and the DC signal is about $2.77 \mathrm{~V}$ and AC signal is around $410 \mathrm{mV}$.

\section{Introduction}

Solar cell has drawn great interest over the past 30 years, and there is a tendency to use it more widely and practically. Visible light communication is also very amazing [1] as a new kind of wireless communication technology with less energy consumption, higher response speed, and more privacy.

Energy gathering and signal detecting system is a new idea. Energy harvesters are widely used in sensor networks. But energy gathering can be hardly seen in the VLC. We noticed that the silicon-based solar panels could receive VLC data and gather energy at the same time.

Research works in this area can be found in [2]; the researchers from Korea used a solar cell as a simultaneous receiver of solar power and visible light communication (VLC) signals. Some research on the efficiency and frequency response of solar cell had been launched.

In our works, solar cell was studied totally under visible light. We set up models similar to the real lighting conditions and run simulations in Matlab/Simulink. Simulation results indicate that it is possible to gather energy and receive data through the same solar panels.

We implement the system using commercial components. Our experiments based on the prototype show that the solar panels can gather energy for low power circuit and detect the VLC signal at the same time.

\section{Model Analysis}

In this section, we analyzed the model of LED and solar cell and then formulated their relationship with some approximations.

2.1. Model of LED Light Source. The LED conforms to Lambert emission rule. When the transmitted optical power is $P_{t}$, the received power $P_{r}\left(\mathrm{w} / \mathrm{m}^{2}\right)$ is expressed as [3]

$$
\begin{aligned}
& P_{r} \\
& = \begin{cases}P_{t} \frac{m+1}{2 \pi d^{2}} \cos ^{m}(\phi) T s(\psi) \cdot g(\psi) \cos (\psi) & 0 \leq \psi \leq \psi_{c} \\
0 & \psi>\psi_{c},\end{cases}
\end{aligned}
$$

where $d$ is the distance between LED and PD, $\phi$ is the irradiance angel, $\psi$ is the incidence angel of $\mathrm{PD}, T s(\psi)$ is the optical filter gain, $g(\psi)$ is the optical concentrator gain, $\psi_{c}$ is the field of view of PD, and $m$ is Lambert emission order.

The SNR for VLC and the illuminance value on PD are given as follows:

$$
\begin{aligned}
\operatorname{SNR} & =\frac{\gamma^{2} P_{\text {rsignal }}^{2}}{\sigma_{\text {shot }}^{2}+\sigma_{\text {thermal }^{2}}+\gamma^{2} p_{\text {rISI }}{ }^{2}} \\
E_{\text {hor }} & =\frac{I(0) \cos ^{m}(\Phi) \cos (\psi)}{d^{2}} .
\end{aligned}
$$




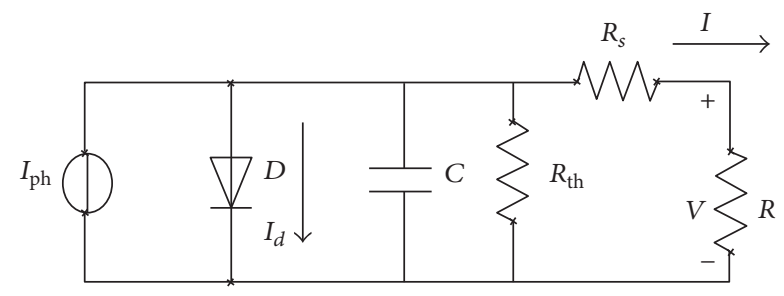

FIgURE 1: The equivalent circuit diagram of a typical solar cell.

2.2. Model of Solar Cell. The equivalent circuit diagram of a typical solar cell is as shown in Figure 1 [4].

It can be formulated as

$$
\begin{aligned}
I= & N_{1} I_{P}-I_{0}\left\{\exp \left[\frac{q\left(V+I R_{s}\right)}{N_{2} A K T}\right]-1\right\}-C \frac{d V}{d t} \\
& -\frac{V+I R_{s}}{R_{\mathrm{th}}}
\end{aligned}
$$

where $N_{1}$ is the number of solar cells in parallel, $N_{2}$ is the series number, $I_{P}$ is the light current, $I_{0}$ is the diode saturation current, $V$ is the output voltage of solar cell, $I$ is the output current, and $A$ is a constant which is typically in the rang 1 to 3. As $R_{\mathrm{th}} \gg R_{s}$, if set

$$
K_{0}=\frac{A K T}{q}
$$

then (3) can be written as

$$
I=N_{1} I_{P}-I_{0}\left\{\exp \left[\frac{\left(V+I R_{S}\right)}{N_{2} K_{0}}\right]-1\right\}-C \frac{d V}{d t} .
$$

For solar cell, the light current is positively proportional with received illuminance power:

$$
I_{P}=\frac{S}{1000} I_{\mathrm{SC}}
$$

$S$ is the illuminance power of solar cell. The standard sun light illuminance power at normal room temperature is $1000 \mathrm{w} / \mathrm{mm}^{2} . I_{\mathrm{SC}}$ is the short circuit current.

We can set $I=0$, so the solar cell works in the open state; then (5) can be expressed as

$$
\begin{aligned}
N_{1} I_{P} & =I_{0}\left[\exp \left(\frac{U_{\mathrm{OC}}}{k_{0} N_{2}}\right)-1\right] \\
I_{0} & =\frac{N_{1} I_{P}}{\exp \left(U_{\mathrm{OC}} / k_{0} N_{2}\right)-1} .
\end{aligned}
$$

2.3. Model of the System. For our system, solar cell is used as the PD. The two models can be connected by making $P_{r}=S$. In this way, (3) can be expressed as follows:

$$
\begin{aligned}
I= & N_{1} \frac{P_{r}}{1000} I_{\mathrm{SC}}-\frac{N_{1} P_{r} I_{\mathrm{SC}}}{\exp \left(U_{\mathrm{OC}} / N_{2} k_{0}\right)-1} \\
& \cdot\left[\exp \left(\frac{U+U / R_{h} \cdot R_{\mathrm{S}}}{N_{2} k_{0}}\right)-1\right] .
\end{aligned}
$$

Combine (5), (6), and (7) together:

$$
\begin{aligned}
I= & \frac{N_{1} P_{r} I_{\mathrm{SC}}}{1000}\left\{1-\frac{1}{1000\left[\exp \left(U_{\mathrm{OC}} / N_{2} k_{0}\right)-1\right]}\right. \\
& \left.\cdot\left[\exp \left(\frac{U+\left(U / R_{n}\right) R_{S}}{N_{2} k_{0}}\right)-1\right]\right\} .
\end{aligned}
$$

$R_{h}$ is the load resistance of solar cell. In conclusion, $k_{1}, k_{2}$, and $k_{3}$ are constants related to $N_{1}, N_{2}, I_{\mathrm{SC}}$, and $U_{\mathrm{OC}}$, so the relationship between $U$ of solar cell and the LED power can be formulated as (11):

$$
\begin{aligned}
I & =\frac{U}{R_{h}} \\
U & = \begin{cases}P_{t} \frac{m+1}{2 \pi d^{2}} \cos ^{m}(\phi) T s(\psi) \cdot g(\psi) \cos (\psi) \frac{1}{k_{1}}\left[1-\frac{1}{k_{2} R_{h}} \exp \left(\frac{U}{k_{3}}\right)\right] & 0 \leq \psi \leq \psi_{c} \\
0 & \psi>\psi_{c} .\end{cases}
\end{aligned}
$$

\section{Results and Discussions}

We set up the two models in Matlab/Simulink and combined them for simulation.

Solar cell model was simulated separately first. The model is based on the equations of (5), (6), and (7). Assuming that it works in the stable room temperature at $298 \mathrm{~K}$, we chose solar cell AM-5308 for our experimental study. Parameters are set in Table 1.
The LED illumination model and Si photocell array model were combined to simulate the practical system. Figure 2 shows that $U_{\mathrm{OC}}$ for $4 \times 4$ and $I_{\mathrm{SC}}$ for $2 \times 8$ are half of values for $4 \times 8$ arrays individually. $U_{\text {OC }}$ of $2 \times 8$ and $4 \times 8$ are $3 \sim 3.5 \mathrm{~V}$, which possibly charge lithium battery. In Figure 3, we got the $2 \times 8$ arrays solar cell's $I$ - $V$ curves through the simulations under different illumination from $300 \mathrm{Lx}$ to $1000 \mathrm{Lx}$. These numbers represent the daily scene illumination value, including living room, library, hospital 
TABLE 1: Parameters for solar cell.

\begin{tabular}{lc}
\hline Parameter & Value \\
\hline Areas & $3 \times 36 \mathrm{~mm}^{2}$ \\
Open circuit voltage & $U_{\mathrm{OC}}=0.3 \mathrm{~V}$ \\
Short circuit current & $I_{\mathrm{SC}}=15 \mathrm{uA}$ \\
Series resister & $R_{s}=0.0052 \Omega$ \\
Standard condition & $E_{v}=100 \mathrm{Lx}$ \\
Parallel number of solar cells & $N_{1}=2$ \\
series number of solar cells & $N_{2}=8$ \\
Load resistance & $R_{h}=0 \sim 5000 \Omega$ \\
Capacity & $20 \mathrm{nF}$ \\
Temperature & $T=298 \mathrm{~K}$ \\
Electronic charge & $q=1.62 e-19 c$ \\
Boltzmann's constant & $1.38066 e-23$ \\
Gain of optical filter & $T_{s}(\psi)=1$ \\
Field of view & $\Psi=60^{\circ}$ \\
Half angel of LED & $\Phi=60^{\circ}$ \\
Lambert constant & $m=1$ \\
Distance & $d=1.0 \mathrm{~m}$ \\
Optical concentrator gain & 1 \\
Power of LED & $15 \mathrm{~W}$ \\
Illuminance & $681 \mathrm{~m} / \mathrm{W}$ \\
\hline
\end{tabular}

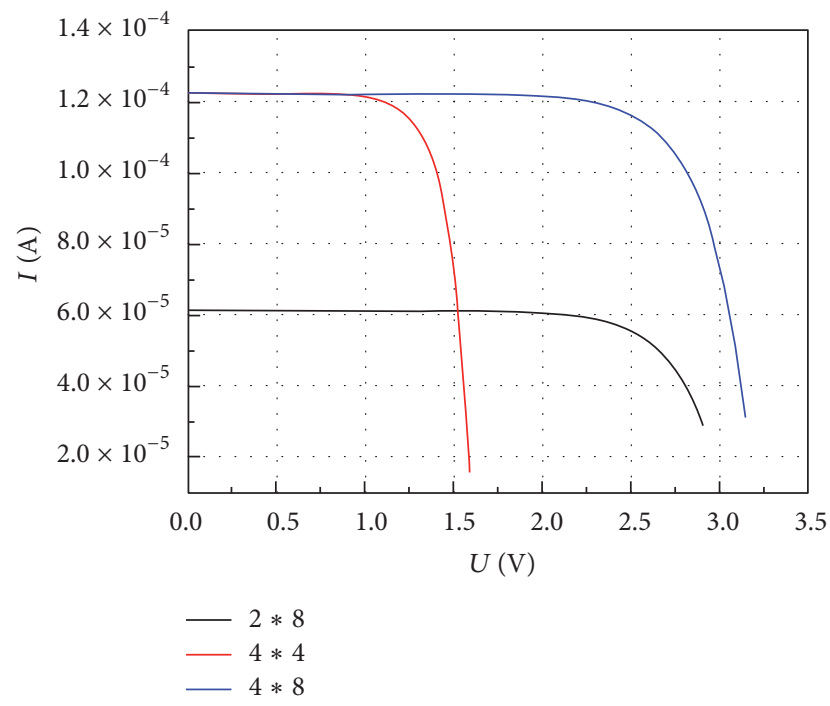

FIGURE 2: $I-V$ curves for different solar cell arrays $\left(E_{v}=300 \mathrm{Lx}\right)$.

operating room, and sports venue. Power properties of different arrays under different illumination values are also simulated in Figures 4 and 5. The output power of $2 \times 8$ arrays under $300 \mathrm{Lx}$ and $50 \mathrm{~K} \Omega$ is $1.4 \times 10^{-4} \mathrm{~W}$. The single receiving area of Si photocell chip is $3 \times 36 \mathrm{~mm}^{2}$. For $2 \times 8$ arrays, the area is $1728 \mathrm{~mm}^{2}$. So the efficiency of the $2 \times 8$ array is $8.1 \%$. The spectral response of Si photocell chip made influence on the received light power as our LED light is mainly made up of blue and yellow.

The output voltage in simulation and experiment is among $2.7 \mathrm{~V}$ to $3.5 \mathrm{~V}$. It increased to saturation state when the

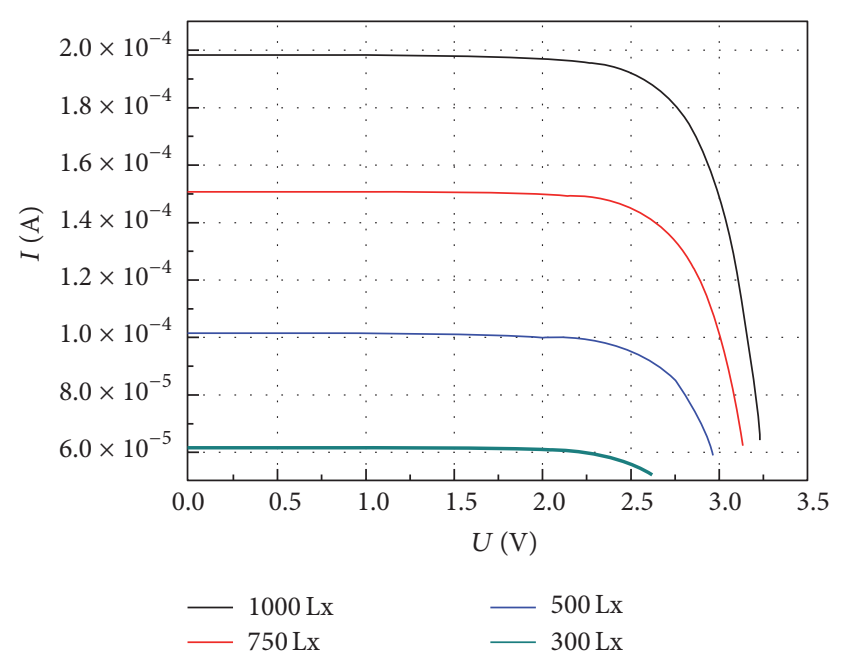

FIGURE 3: $I$ - $V$ curves of $2 \times 8$ arrays under different illumination.

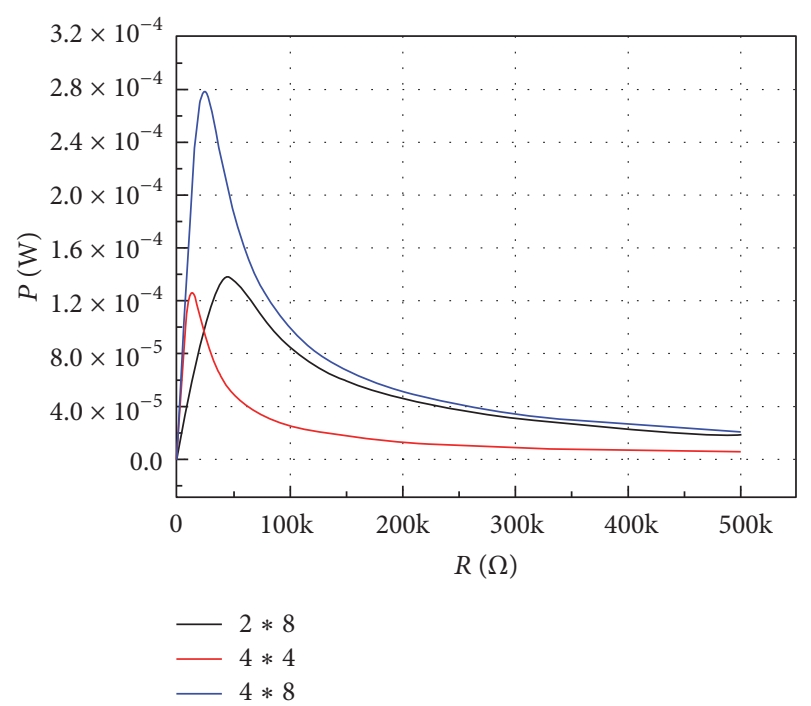

Figure 4: $P$-R curves for different solar cell arrays $\left(E_{v}=300 \mathrm{Lx}\right)$.

illumination value is above $500 \mathrm{Lx}$. It is stable for supplying power. The simulation value and experiment matched perfectly in Figure 6.

Then, a square signal as in Figure 7 is modulated on LED as the transmitting data. The period of the square signal is 0.1 s. The duty cycle is $50 \%$.

The output power of the solar cell depends on the load resistance. The maximum output power about $1.2 \times 10^{-3} \mathrm{~W}$ can be achieved, when load resistance is $4 \mathrm{k} \Omega$, under illumination at $300 \mathrm{~lx}$. The output power of solar cell with different load resistance is shown in Figure 8; the $x$-axis unit is $10 \mathrm{~K} \Omega$.

The output voltage of solar cell rises to $2.5 \mathrm{~V}$ after several pulses. The waveform of output voltage of solar cell under continuous pulse modulation is shown in Figure 9; the $x$-axis unit is $1 \mathrm{~S}$.

An energy gathering and signal detecting system was demonstrated as Figure 10. To fit the working condition of solar cell, we used a $15 \mathrm{~W}$ LED which could simulate the 


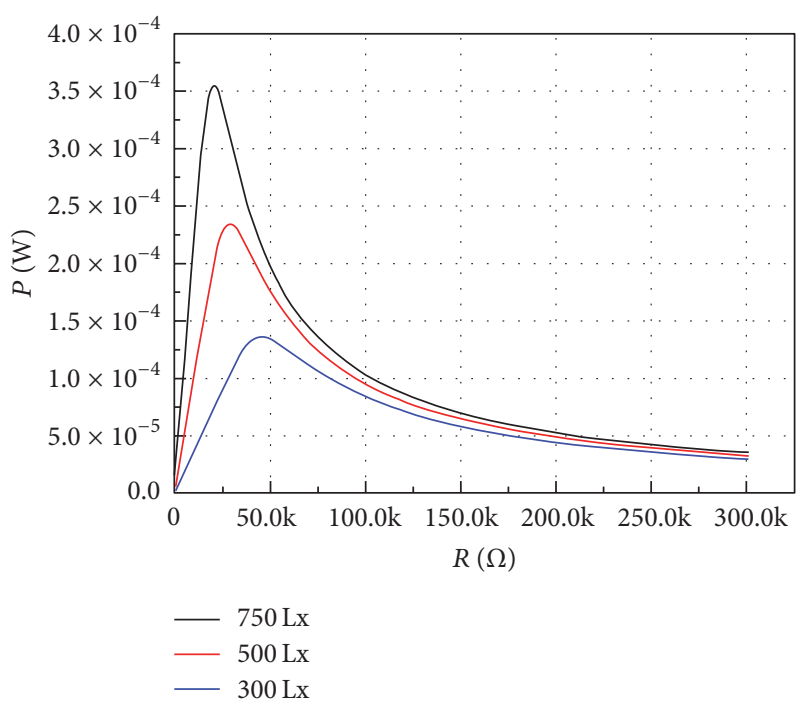

Figure 5: $P$ - $R$ curves under different illumination.

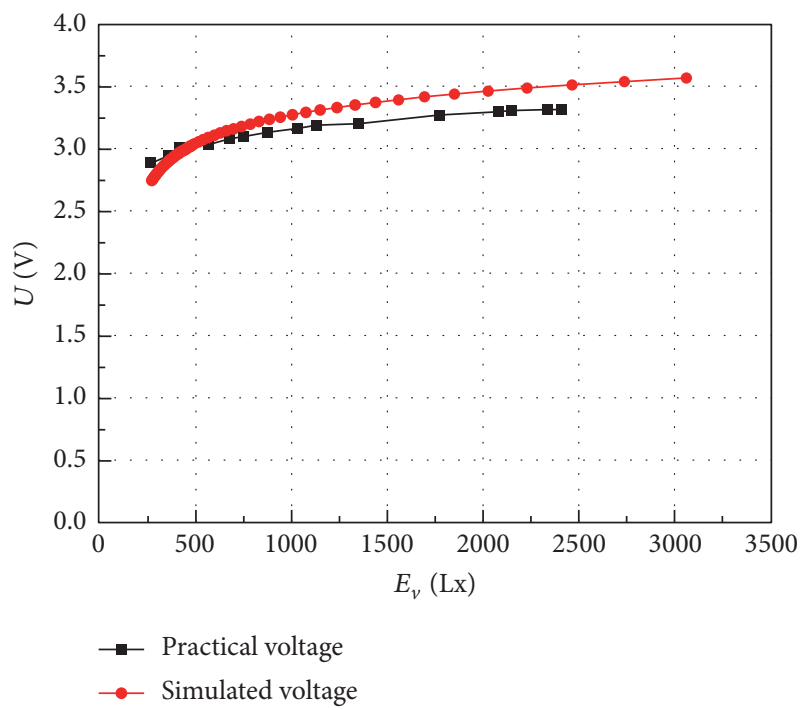

FIGURE 6: Comparison of simulation and experiments result for voltage and illumination.

different indoor lighting conditions. The distance between the $2 \times 8$ photocell array and the $15 \mathrm{w}$ LED is $1.8 \mathrm{~m}$. The illumination value on photocell was $690 \mathrm{~lx}$, when the LED was not modulated. The illumination value on photocell was $637.5 \mathrm{~lx}$, when the LED was modulated. The baud rate of computer's output was 19200 . The output data was the repetition of "A5" in HEX form and the polarity was reversed by RS485 converter chip. The yellow line in Figure 11 represents a DC coupled output signal of the silicon photocell which is about $2.77 \mathrm{~V}$. The green line in Figure 11 represents the AC coupled output signal of the silicon photocell, filtered by a $0.1 \mu \mathrm{F}$ coupling capacitor. And the AC signal is around $410 \mathrm{mV}$. The baud rate and AC amplitude could be higher after one stage amplifier circuit [5].
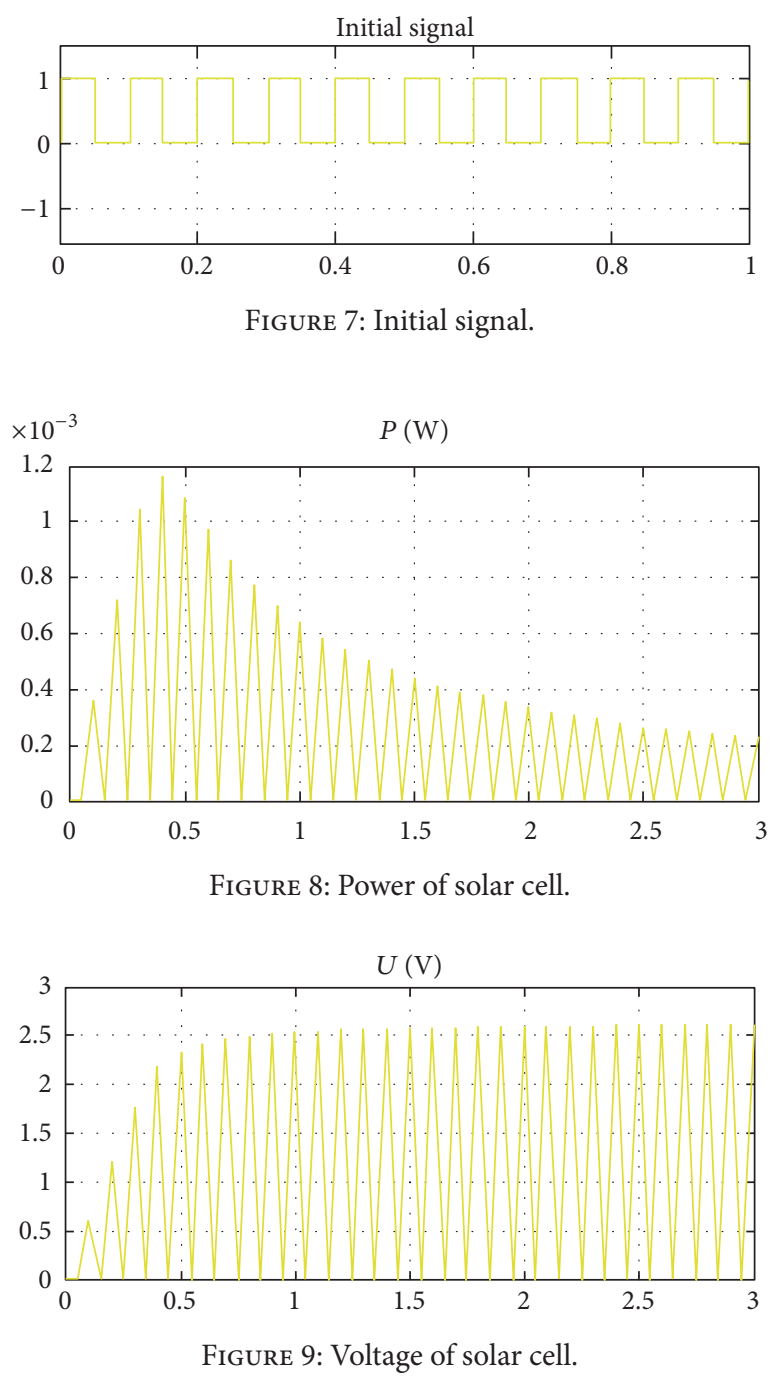

\section{Conclusion}

In our works, we set up a model of solar cell VLC system which was simulated in Matlab/Simulink. We had verified the correction of the model and gave reasonable design to optimize the system.

The energy gathering and signals detecting system was demonstrated. The data rate of it is 19200 bps. The DC voltage of photocell was about $2.77 \mathrm{~V}$ which is enough for low voltage power supply circuits. The AC voltage of photocell was about $410 \mathrm{mV}$ and could be optimized by one stage amplifier circuit. It was proved that solar cell can act as energy converting and detecting device simultaneously in VLC system.

The channel influences [6], response of solar cell to frequency, room lighting conditions, and other factors were ignored in our model. Further studies can take these factors into consideration. At the same time, we will optimize the design for the actual application.

\section{Competing Interests}

The authors declare that they have no competing interests. 


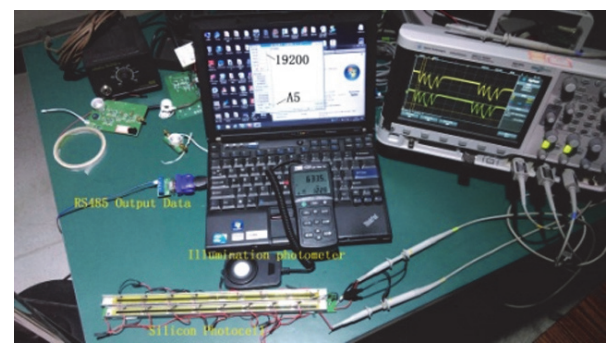

FIGURE 10: Energy gathering and signal detecting demo system.

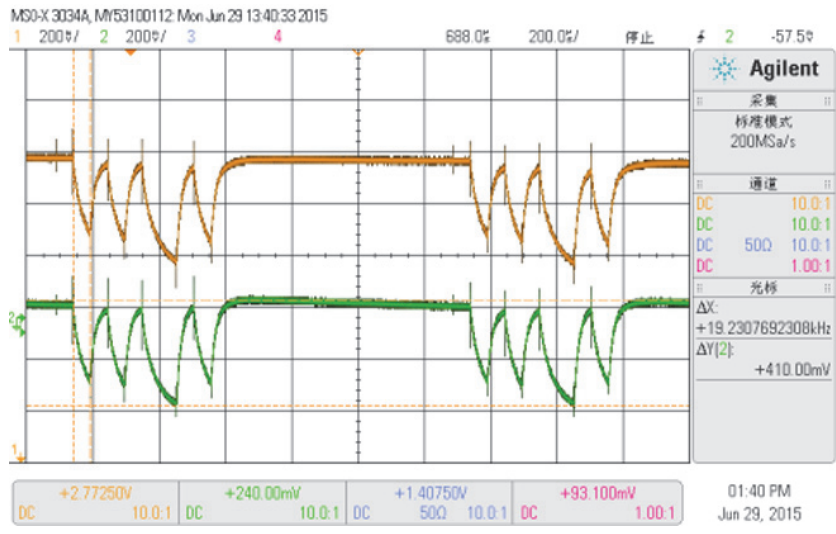

FIGURE 11: Output signals of silicon photocell.

\section{Acknowledgments}

This work is supported in part by the National Key Basic Research Program of China (Grant no. 2013CB329204), in part by the National High Technology Research and Development Program of China (Grant no. 2015AA033303), and in part by Science and Technology Planning Project of Guangdong Province, China (Grant no. 2014B010120004).

\section{References}

[1] A. Jovicic, J. Li, and T. Richardson, "Visible light communication: opportunities, challenges and the path to market," IEEE Communications Magazine, vol. 51, no. 12, pp. 26-32, 2013.

[2] S.-M. Kim, J.-S. Won, and S.-H. Nahm, "Simultaneous reception of solar power and visible light communication using a solar cell,” Optical Engineering, vol. 53, no. 4, Article ID 046103, 2014.

[3] T.-H. Do and M. Yoo, "Optimization for link quality and power consumption of visible light communication system," Photonic Network Communications, vol. 27, no. 3, pp. 99-105, 2014.

[4] E. Koutroulis, K. Kalaitzakis, and N. C. Voulgaris, "Development of a microcontroller-based, photovoltaic maximum power point tracking control system," IEEE Transactions on Power Electronics, vol. 16, no. 1, pp. 46-54, 2001.

[5] J. Guo, X. Chen, H. Li, Y. Huang, and H. Chen, "The response properties analysis of silicon photovoltaic cell array in visible light communication system," Optoelectronics Laser, vol. 26, no. 3, pp. 475-479, 2015.

[6] K. Lee, H. Park, and J. R. Barry, "Indoor channel characteristics for visible light communications," IEEE Communications Letters, vol. 15, no. 2, pp. 217-219, 2011. 

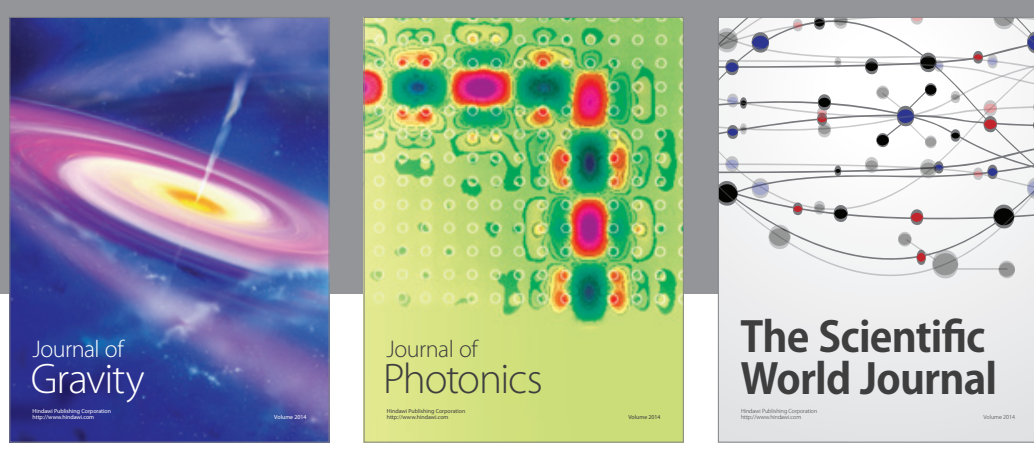

The Scientific World Journal
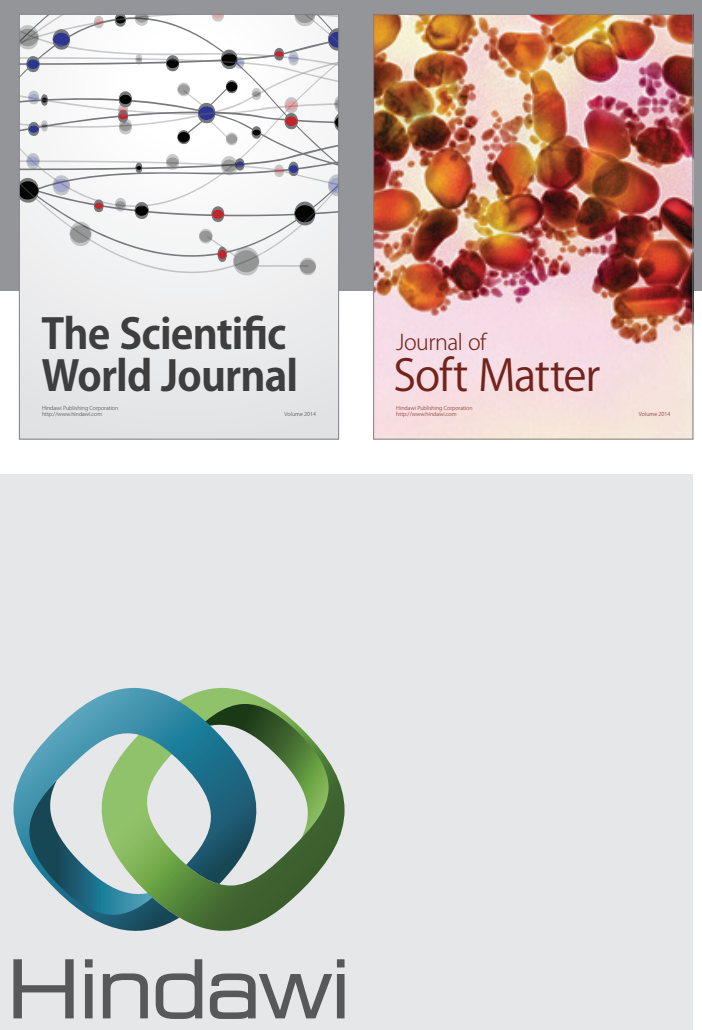

Submit your manuscripts at

https://www.hindawi.com
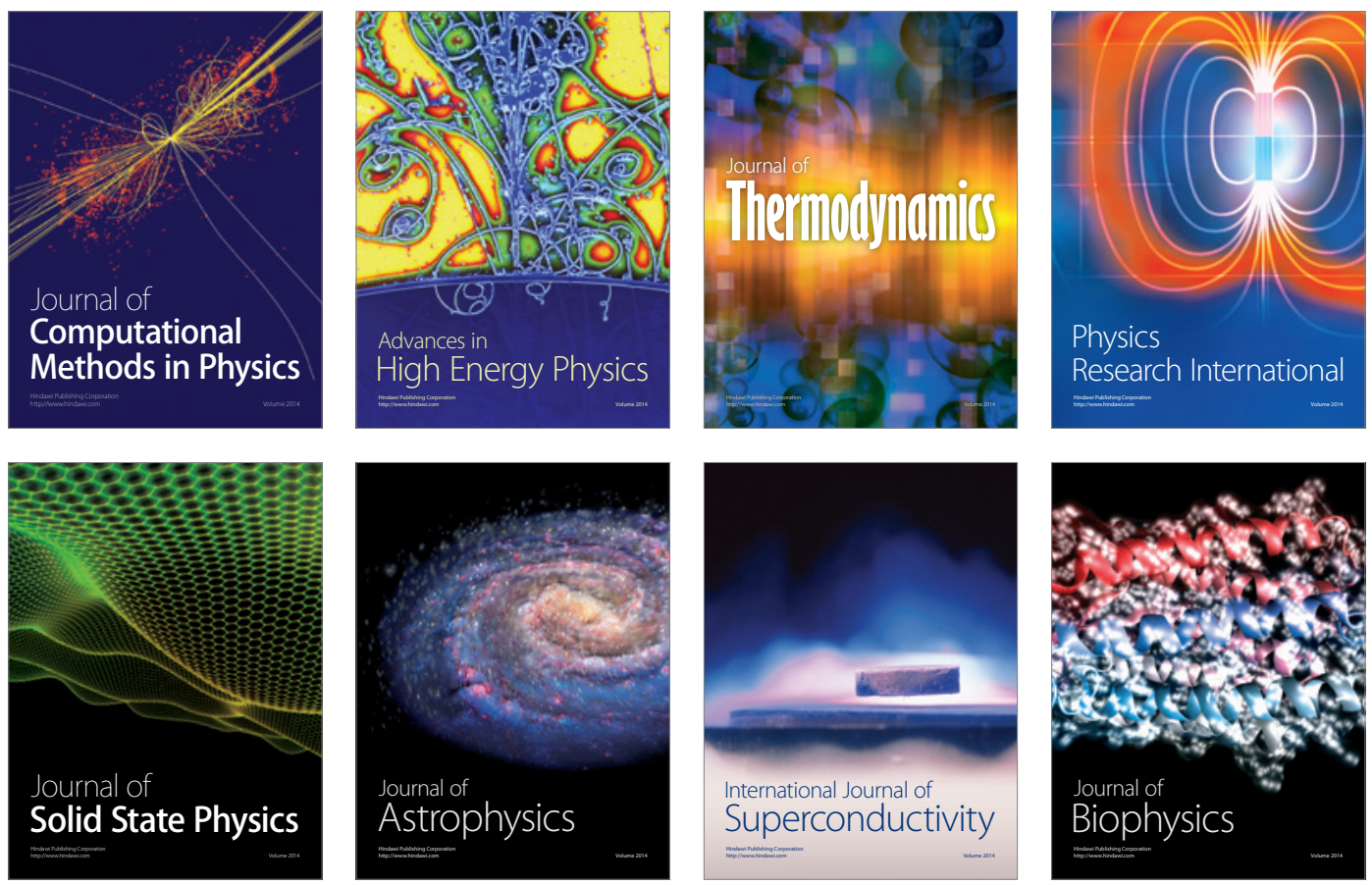
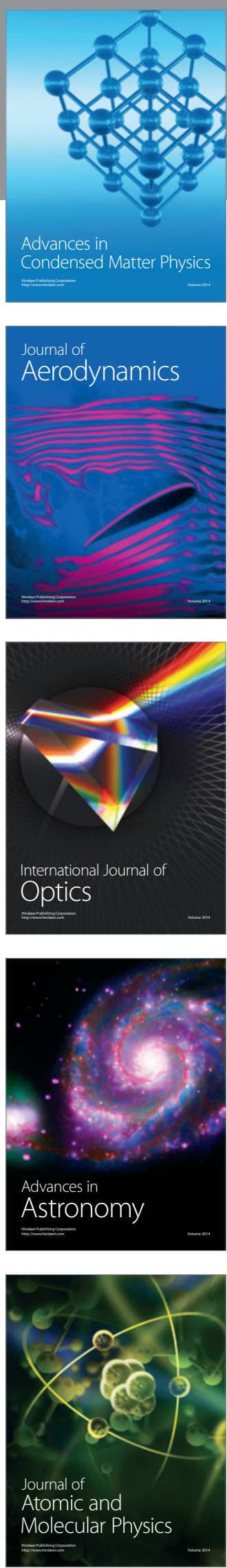